\title{
AUTHENTHIC PROBLEM BASED LEARNING (aPBL) UNTUK MENINGKATKAN KEMAMPUAN BERPIKIR SISWA
}

\author{
Muhammad Nur Hudha ${ }^{1}$, Sudi Dul Aji ${ }^{1}$, Anggita Permatasari ${ }^{1}$, \\ Rizki Dian Purnama ${ }^{1}$ \\ ${ }^{1}$ Prodi Pendidikan Fisika, Universitas Kanjuruhan Malang \\ E-mail: muhammadnurhudha@unikama.ac.id
}

\begin{abstract}
The purpose of physics learning at the school level is directed to develop the students' thinking skill. This study aimed to improve the students' critical thinking skill and students' problem solving skill through aPBL (authenthic Problem Based Learning) learning. This study used classroom action research designed by Kemmis \& Mc Taggart with the stages; problem identification, action planning, action, observation, and reflection. The research data were obtained in the form of the data of students' problem-solving skill and critical thinking. The data in this research were analyzed qualitatively and quantitatively. The results showed that the application of aPBL (authentic Problem Based Learning) could improve the students' critical thinking skill and students' problem solving skill. This improvement could be seen from the average score of critical thinking test and problem solving skill test that had been carried out.
\end{abstract}

Keywords: aPBL, thinking skill, physics

Tujuan pembelajaran fisika pada tingkat sekolah diarahkan untuk mengembangkan kemampuan berpikir (Hudha dkk, 2016), dan mengembangkan penguasaan konsep untuk dapat digunakan sebagai bekal pendidikan yang lebih tinggi (Depdiknas, 2006). Guru sebagai pembentuk karakter siswa harus mengajar dengan cara mengembangkan kemampuan berpikir kritis (Ayu, 2014) dan memecahkan masalah kompleks (Walsh dkk, 2007).

Pada abad 21 ini seorang guru dituntut untuk mampu menguasai dan melatih siswanya lebih kreatif dan inovatif serta unggul dalam afektif, oleh karena itu guru dituntut untuk mampu memahami, menilai dan berpartisipasi dalam menghasilkan pengetahuan baru serta proses yang baru pula. Pada pembelajaran Fisika, selain mengajarkan untuk memahami pengetahuan, siswa juga perlu diajarkan mengembangkan kemampuan pemecahan masalah sehingga siswa terbiasa berfikir kritis secara ilmiah dalam kehidupan sehari-hari (Hudha dkk, 2012).

Kenyataan di lapangan menunjukkan kemampuan berpikir siswa pada pelajaran Fisika masih rendah. Kemampuan berpikir yang masih rendah ini salah satunya diakibatkan oleh kesalahan konsep 
yang terjadi pada siswa (Hudha dkk, 2016). Sehingga untuk meminimalisir kesalahan konsep tersebut kemampuan berpikir siswa perlu dikembangkan sejak masa sekolah (Hudha dkk, 2012).

Berdasarkan hasil observasi dan wawancara dengan guru SMP dan SMA di Malang, yaitu kemampuan siswa dalam memecahkan masalah serta berpikir kritis ketika menghadapi permasalahan masih tergolong rendah. Hal ini juga terjadi pada saat mengerjakan soal-soal materi, siswa hanya bisa mengerjakan soal yang sesuai dengan contoh soal yang sudah dibahas bersama guru. Siswa masih kesulitan kalau permasalahan tersebut dibawa kedalam situasi baru.

Salah satu model pembelajaran yang berorientasi pada masalah dan mengembangkan kemampuan berpikir adalah Problem Based Learning (Arends, 2012). PBL merupakan model pembelajaran yang menekankan pada permasalahan berdasarkan pada kehidupan seharihari (Hudha, 2012). PBL dapat mengembangkan kemampuan berfikir kritis, menganalisis dan memecahkan permasalahan yang kompleks atau permasalahan kontekstual (Arends, 2012).

Barrows \& Lynda (2007) mengkolaborasikan model Problem Based Learning (PBL) dengan pendekatan authentic learning, yang lebih sering dikenal dengan model authentic Problem Based Learning (aPBL). Penambahan istilah authentic dimaksudkan untuk mencerminkan tuntutan dunia kerja sebagai proses belajar. Model aPBL didukung dengan adanya pendidikan otentik dan masalah sebagai simulasi keadaan yang akan dihadapi di dunia nyata. aPBL adalah sebuah model pembelajaran yang berpusat pada siswa yang merangsang siswa untuk memperoleh dan mengaplikasikan pengetahuan dan keterampilan yang mereka butuhkan termasuk pemecahan masalah (Rohanum, 2013; Amelia, 2014). Model aPBL dirancang dengan tujuan agar siswa terampil menggunakan pengetahuan dan keterampilan ketika menghadapi masalah baru serta bekerja secara efektif dalam kelompok Barrows \& Lynda (2007). Oleh karena itu, penerapan aPBL diharapkan dapat meningkatkan kemampuan pemecahan masalah dan berpikir kritis siswa

\section{METODE}

Jenis penelitian yang digunakan berupa Penelitian Tindakan Kelas (PTK). Rancangan penelitian mengadaptasi dari bagan Kemmis-Mc Taggart (dalam Arikunto, 2011, 16) ditunjukkan pada Gambar 1.

Penelitian ini dilakukan dalam konteks kelas yang bertujuan memperbaiki proses pembelajaran sehingga dapat meningkatkan kemampuan memecahkan masalah dan berpikir kritis. Tindakan yang dilakukan adalah penerapan authentic Problem Based Learning (PBL). Penelitian ini dilaksanakan pada kelas XIA5 SMAN 1 Singosari dan di SMPN 3 Kepanjen tahun pelajaran 2015/2016.

Data yang diperoleh berupa data kemampuan memecahkan masalah dan berpikir kritis. Data dikumpulkan dengan cara pengamatan parsitipatif, observasi, data penelitian, dan tes. Instrumen 
penelitian berupa instrumen pembelajaran, instrumen pengukuran penelitian, dan catatan lapangan. Instrumen pembelajaran berupa silabus, LKS, dan media pembelajaran yang mendukung. Instrumen pengukuran penelitian butir soal yang dibuat berdasarkan indikator kemampuan memecahkan masalah dan berpikir kritis. Catatan lapangan yang berupa foto, video, dan catatan pribadi peneliti tetapi tidak tercantum dalam format lembar observasi.

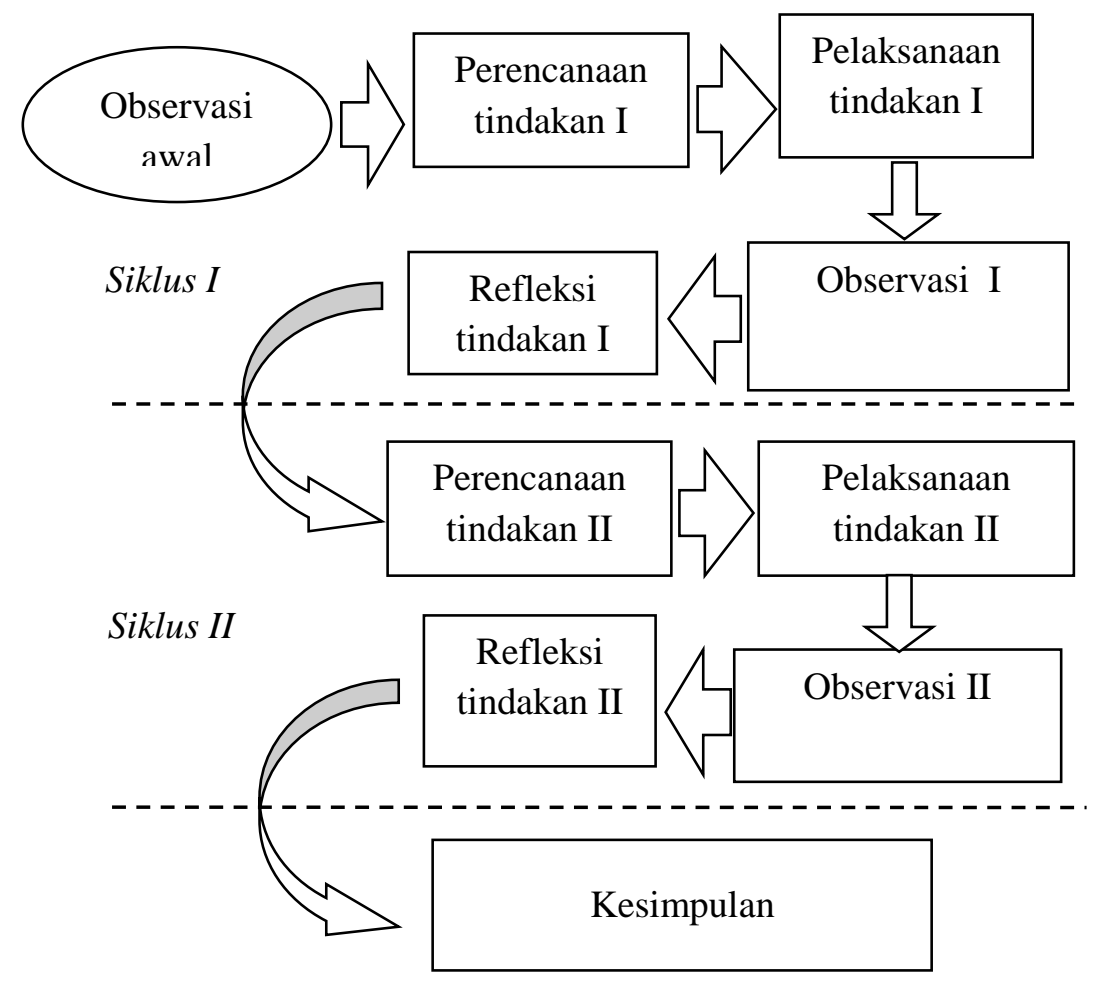

Gambar 1. Diagram Prosedur Penelitian Tindakan Kelas Model Kemmis \& Mc Taggart

Analisis data yang digunakan dalam penelitian ini adalah analisis data kualitatif dan analisis data kuantitatif. Analisis data kualitatif digunakan untuk menganalisis paparan data yang mengacu pada catatan lapangan, dan nilai. Hasil analisis data disajikan secara naratif. Analisis data kuantitatif digunakan untuk mendukung keberhasilan penelitian yang dijabarkan dalam bentuk persentase dan angka.

\section{HASIL DAN PEMBAHASAN}

a. Kemampuan Memecahkan Masalah

Peningkatan kemampuan pemecahan masalah siswa dapat dilihat pada Tabel 1. 
Tabel 1. Perbandingan rata-rata nilai kemampuan memecahkan masalah tiap siklus

\begin{tabular}{|c|c|c|}
\hline \multirow[t]{2}{*}{ Indikator kemampuan memecahkan masalah } & \multicolumn{2}{|c|}{$\begin{array}{c}\text { Rata-rata nilai tes } \\
\text { memecahkan masalah }\end{array}$} \\
\hline & Siklus I & Siklus I \\
\hline $\begin{array}{l}\text { Menggunakan proses berpikir untuk memecahkan } \\
\text { kembali masalah yang sudah diketahui }\end{array}$ & $74,86 \%$ & $85,95 \%$ \\
\hline $\begin{array}{l}\text { Mengumpulkan fakta tentang masalah dan } \\
\text { informasi yang diperlukan }\end{array}$ & $69,46 \%$ & $80,14 \%$ \\
\hline $\begin{array}{l}\text { Membuat referensi atau memberikan penyelesaian } \\
\text { alternatif dan menguji penyelesaian }\end{array}$ & $75,81 \%$ & $99,73 \%$ \\
\hline $\begin{array}{l}\text { Merangkum penjelasan menjadi lebih sederhana } \\
\text { dan mengeleminasi hal-hal yang tidak sesuai }\end{array}$ & $71,76 \%$ & $99,19 \%$ \\
\hline $\begin{array}{l}\text { Memberikan solusi ulang untuk membuat } \\
\text { kesimpulan }\end{array}$ & $43,38 \%$ & $96,89 \%$ \\
\hline
\end{tabular}

Hasil perhitungan kemampuan pemecahan masalah diambil dari nilai tes yang dilakukan pada akhir siklus. Pada siklus I rata-rata persentase kemampuan pemecahan masalah adalah $67,05 \%$ dengan kriteria cukup dan hasil ini belum memenuhi target keterlaksanaan yang diinginkan, yaitu $\geq 75 \%$. Sedangkan pada siklus II, rata-rata persentase kemapuan pemecahan masalah mengalami peningkatan yakni $92,38 \%$ dengan kriteria baik sekali dan hasil ini sudah memenuhi target keterlaksanaan yang diinginkan, yaitu $\geq 75 \%$.

Hasil penelitian ini sesuai dengan penelitian yang dilakukan sebelumnya yaitu (Yuliati, 2012; Rohanum, 2013), pembelajaran dengan aPBL dapat meningkatkan hasil belajar dalam aspek kognitif, afektif, dan psikomotor. Peningkatan tersebut terjadi karena aPBL memfasilitasi siswa untuk aktif belajar secara mandiri dengan menggunakan fenomena fisika secara langsung. Selain itu, aPBL juga memberi kesempatan kepada siswa untuk menyelesaikan masalah secara mandiri dalam kelompok belajar.

Efektivitas aPBL bagi kemampuan analisis dan pemecahan masalah sesuai dengan pendapat Barrows \& Lynda (2007). aPBL sangat efektif untuk mengembangkan kemampuan pemecahan masalah karena berorientasi pada masalah yang nyata. Selain itu, Barrows \& Lynda (2007) menyatakan bahwa pembelajaran aPBL dirancang dengan tujuan agar siswa terampil menggunakan pengetahuan untuk memecahkan masalah baru, dan bekerja secara efektif dalam team. Sesuai juga dengan pernyataan Herrington \& Herrington (2006) bahwa pembelajaran yang otentik merupakan pembelajaran yang berfokus pada penciptaan lingkungan belajar berdasarkan dunia nyata, dengan cara menggali masalahmasalah yang komplek 
menyelesaikannya, diperlukan penyelidikan yang berkelanjutan dengan memanfaatkan berbagai sumberdaya dan perspektif teori.

\section{b. Kemampuan Bepikir Kritis}

Tes berpikir kritis dilakukan pada akhir setiap siklus. Tes ini terdiri dari 11 soal pilihan ganda dan 4 soal campuran. Skor total soal tersebut adalah 25. Rata-rata tes pada siklus I adalah 72,56 dan pada siklus II adalah 81,33. Pencapaian indikator berpikir kritis tiap indikator pada siklus I dan siklus II dapat dilihat pada Tabel 2.

Tabel 2. Perbandingan rata-rata nilai berpikir kritis tiap siklus

\begin{tabular}{lcc}
\hline \multirow{2}{*}{\multicolumn{1}{c}{ Indikator berpikir kritis }} & \multicolumn{2}{c}{$\begin{array}{c}\text { Rata-rata nilai tes } \\
\text { berpikir kritis }\end{array}$} \\
\cline { 2 - 3 } & Siklus I & Siklus II \\
\hline Menjawab pertanyaan yang membutuhkan alasan & 58,33 & 75 \\
Memberikan argumen & 77,77 & 78,48 \\
Membuat nilai keputusan & 88,33 & 86,11 \\
Memutuskan suatu tindakan & 73,14 & 87,78 \\
\hline
\end{tabular}

Berdasarkan hasil rata-rata nilai tes pada siklus I dan siklus II diperoleh peningkatan sebesar 8,77. Hal ini menunjukan adanya peningkatan pemahaman siswa setelah diajar menggunakan aPBL pada siklus I dan siklus II.

Indikator kemampuan berpikir kritis ini menggunakan indikator Ennis (1996). Indikator kemampuan berpikir kritis yang digunakan dalam penelitian ada 4, yaitu (1) bertanya dan menjawab pertanyaan yang membutuhkan alasan, (2) menganalisis argumen, (3) membuat nilai keputusan dan (4) memutuskan suatu tindakan. Pengukuran tes berpikir kritis ini menggunakan soal campuan yaitu 11 soal pilihan ganda dan 4 soal uraian. Instrumen pengukuran kemampuan berpikir kritis disusun berdasarkan hasil penelitian Ariyati (2010) yang menyatakan bahwa tes kemampuan berpikir kritis dapat menggunakan soal campuran yang disusun berdasarkan indikator berpikir kritis. Senada dengan hal tersebut Starko (dalam Piaw, 2010) menyatakan bahwa berpikir kritis dapat diidentifikasi, diukur, dan diwakili oleh skor.

Tes berpikir kritis dilakukan pada setiap akhir siklus. Pada tes siklus I kemampuan berpikir kritis siswa cenderung mengalami kesalahan pada kemampuan merumuskan masalah. Hal ini terbukti pada saat pembelajaran siswa kesulitan dalam merumuskan masalah yang ada diawal pelajaran yang diajukan guru. Glaser (dalam Fisher, 2009:3) mengungkapkan bahwa kemampuan berpikir kritis merupakan sikap mau berpikir secara mendalam tentang masalah-masalah melalui metode-metode pemeriksaan dan penalaran yang logis terhadap masalah tersebut.

Pada siklus II kemampuan berpikir kritis siswa telah mengalami peningkatan. Kemampuan siswa dalam bertanya dan menjawab pertanyaan yang membutuhkan alasan mengalami peningkatan pada siklus II. Hal ini dikarenakan pada saat menjawab pertanyaan dari guru siswa sudah mampu memberikan alasan 
yang mendukung jawaban tersebut, sehingga ketika dilaksanakan tes berpikir kritis siswa sudah mampu menjawab pertanyaan dengan disertai alasan yang mendukung jawaban siswa tersebut. Glasser (dalam Fisher, 2009) menyatakan bahwa kemampuan berpikir kritis adalah upaya untuk memeriksa setiap keyakinan atau pengetahuan berdasarkan bukti pendukungnya dan kesimpulan-kesimpulan lanjutan yang diakibatkanya.

\section{SIMPULAN DAN SARAN}

Berdasarkan hasil penelitian dan pembahasan yang diuraikan, maka dapat disimpulkan : 1) Penerapan aPBL (authentic Problem Based Learning) dapat meningkatakan kemampuan berpikir kritis siswa. Peningkatan ini dilihat dari rata-rata nilai tes berpikir kritis yang telah dilakukan. Berdasarkan hasil rata-rata nilai tes pada siklus I dan siklus II diperoleh peningkatan sebesar 8,77. Aspek indikator berpikir kritis meliputi bertanya dan menjawab pertanyaan yang membutuhkan alasan, menganalisis argumen, membuat nilai keputusan dan memutuskan suatu tindakan; 2) Kemampuan pemecahan masalah siswa juga dapat meningkat. Hal tersebut nampak dari rata-rata nilai tes siklus I adalah $67,05 \%$, sedangkan nilai rata-rata hasil tes siklus II adalah 92,38\%. Hasil ini membuktikan bahwa persentase rata-rata indikator kemampuan pemecahan masalah dengan menggunakan model pembelajaran authentic Problem Based Learning (aPBL) telah mencapai indikator keberhasilan yakni $\geq 75 \%$ dengan kriteria baik

\section{DAFTAR PUSTAKA}

Amelia, R. (2014). Pengaruh authentic Problem Based Learning (aPBL) terhadap Kemampuan Pemecahan Masalah Mahasiswa Pendidikan Fisika Universitas Negeri Malang. Skripsi. Malang: Program Studi Pendidikan Fisika Universitas Negeri Malang.

Arends, R. I. (2010). Learning to Teach: 9th Edition. New York: McGraw-Hill.

Arikunto, S. (2011). Penelitian Tindakan Kelas. Jakarta: Bumi Aksara.

Ariyati, E. (2010). Pembelajaran Berbasis Praktikum Untuk Meningkatkan Kemampuan Berpikir Kritis Mahasiswa. Jurnal Pendidikan Matematika dan IPA, Vol.1, No.2, from http://jurnal.untan. ac.id/index.php/PMP/article/vi ew/194

Ayu, N. F. (2014). Pengaruh Authentic Problem Based Learning (APBL) Terhadap Kemampuan Berpikir Kritis Mahasiswa Prodi Pendidikan Fisika Universitas Negeri Malang. Tesis. Universitas Negeri Malang.

Barrows, H.S. \& Lynda, W.K.N. (2007). Principles and Practice of aPBL. Jurong: Pearson Prentice Hall.

Depdiknas. (2006). Permen Diknas No. 22. Kurikulum Fisika (Standar Isi). Jakarta: Depdiknas. 
Ennis, R. H. (1996). Critical Thinking. New Jersey: Prentice-Hall.

Fisher. A. (2009). Berpikir Kritis Sebuah Pengantar. Jakarta: Erlangga.

Herrington, $\mathrm{T}$ \& Herrington, $\mathrm{J}$. (2006). Authentic Learning Environtments in Higher Education. Tukkish Online Journal of Distance Education-TOJDE, Vol.7, No.1, 175-191.

Hudha, M.N., Yuliati, L. \& Sutopo. (2016). Perubahan Konseptual Fisika dengan Authentic Problem melalui Integrative Learning pada Topik Gerak Lurus pada SMA Suryabuana Malang. Jurnal Inspirasi Pendidikan, Vol.6, No.1, 733743.

Hudha, M.N., Yuliati, L., \& Haryoto, D. (2012). Authentic Learning untuk Meningkatkan Kemampuan Berpikir Kritis Calon Guru Fisika. Prosiding Seminar Nasional MIPA dan Pembelajaran (pp. 180-186).
Piaw, C.Y. (2010). Building a Test to Asses Creative and Critical Thinking Simultaneously. Procedia Sosial and Behavioral Sciences 2 (pp. 551-559).

Rohanum, E. (2013). Pengaruh Authentic-Problem Based Learning Terhadap Kemampuan Pemecahan Masalah Fisika Ditinjau Dari Kemampuan Awal Peserta Didik MAN 1 Malang. Tesis. Malang: PPs UM.

Walsh, L.N., Howard R.G., \& Bowe, B. (2007). Phenomenographic study of students' problem solving approaches in physics. Physical Review Special Topics - Physics Education Research, Vol. 3.

Yuliati, L. (2012). Authentic Problem Based Learning untuk Meningkatkan Hasil Belajar Fisika Siswa SMA. Makalah, Seminar Nasional MIPA dan Pembelajaran. Fakultas Matematika dan Ilmu Pengetahuan Alam Universitas Negeri Malang. 